\title{
Giras de organización, la respuesta sindical a la estructura agraria. Entre Ríos, 1917-1939
}

\section{Organizational tours, the union response to the agrarian structure. Entre Ríos, 1917-1939}

\author{
Rodolfo M. Leyes \\ Universidad Autónoma de Entre Ríos \\ Facultad de Humanidades, \\ Artes y Ciencias Sociales- Sede Uruguay \\ Consejo Nacional de Investigaciones Técnicas y Científicas \\ Entre Ríos, Argentina \\ (iD) https://orcid.org/0000-0001-7112-7832 \\ leyes.rodolfo@gmail.com
}

\begin{abstract}
Resumen
Las primeras décadas del siglo veinte conocieron un hecho hasta entonces espontáneo y aislado, la creación de sindicatos a escala nacional dirigido por un plan. Si bien la ciudad de Buenos Aires tuvo preeminencia en la actividad gremial, vemos a partir de la hegemonía de los sindicalistas a mediados de la década de 1910, un crecimiento exponencial en el interior argentino. El avance de los sindicalistas se reflejó en un aumento de la conflictividad obrera. Sin embargo, precisó de un paso previo, la creación del aparato organizativo para la lucha económica. La construcción de nuevos sindicatos fue ardua y precisó de la predisposición militante de aquellos gremialistas que se movilizaron por el interior argentino con el objetivo de fundar nuevos organismos obreros. Estos militantes crearon una táctica que se sostuvo en el tiempo hasta por lo menos fines de la década del treinta, las giras de organización realizadas por algunos militantes, muchas veces en solitario, que recorrían diferentes localidades, se reunían con obreros y creaban nuevos sindicatos.
\end{abstract}

Cómo citar este artículo/ How to cite this article: Leyes, R. (2021). Giras de organización, la respuesta sindical a la estructura agraria. Entre Ríos, 1917-1939. Revista de Historia Americana y Argentina, 56 (2), pp. 105-137. https://doi.org/10.48162/rev.44.013 
Palabras clave: Movimiento obrero; Giras de organización; Sindicalismo; Provincia de Entre Ríos.

\begin{abstract}
The first decades of the twentieth century saw a spontaneous and isolated event until then, the creation of national-scale unions led by a plan. Although the city of Buenos Aires had a preeminence in union activity, we see from the hegemony of the syndicalist tendency in the mid-1910s, an exponential growth in the interior of Argentina. The advance of the trade unionists was reflected in an increase in the workers' conflict, however it required a previous step, the creation of the organizational device for the economic struggle. The construction of new unions was arduous and precise of the militant predisposition of those unionists who mobilized through the interior of Argentina with the objective of founding new workers' organizations. These militants created a tactic that was sustained over time until at least the thirties. Organizational tours were the key to success. Activity carried out by some militants, often alone, registering different locations, meeting with workers and creating new unions.
\end{abstract}

Key words: Worker movement; Organization tours; Unionism; Province of Entre Ríos.

Recibido: 02/11/2020 Aceptado: 01/11/2021

\title{
Introducción
}

Conocemos la historia de los sindicatos de la Capital Federal de la República Argentina con cierto grado de detalle, los nombres de los militantes, las fechas de sus fundaciones, sus luchas más importantes, la extracción ideológica de sus obreros y las oposiciones internas, hasta las calles y direcciones de los locales sindicales. Pero la historia del interior argentino se nos presenta aún como una incógnita. Inclusive en algo tan simple como saber cuál fue la extensión territorial. En esa dirección corresponden las preguntas ¿Cuál fue la metodología para organizar espacios que no tenían núcleos sindicales? ¿Cómo se organizó sindicalmente al proletariado que habitaba pequeños poblados dispersos? Es decir, ¿cómo se organizaron los obreros de un capitalismo fuertemente agrario? Creemos que las giras de organización responden estas preguntas. 
Las giras de organización eran viajes que realizaban cuadros sindicales a puntos donde no existía organización previa o esta era muy débil. Si bien en el territorio de estudio existen casos de militantes que llegaron a sus costas a principios del siglo $X X$ con intenciones de agitación ${ }^{1}$, no fue hasta mediados de la década de 1910, cuando la corriente sindicalista tomó el control de los gremios más importantes del movimiento obrero (Marotta, 1961, T. II; Belkin, 2018), y las giras tomaron nuevos bríos.

La hegemonía sindicalista es fundamental para entender al movimiento obrero entrerriano, no solo de este momento constitutivo, sino más allá, cuando la provincia será uno de los grandes (y últimos) bastiones del sindicalismo en la Argentina. La referencia a esta persistencia ideológica durante tres décadas no es aleatoria. Se halla una relación entre las giras y la continuidad sindicalista. Las primeras organizaciones obreras entrerrianas fueron establecidas por militantes de esa extracción a partir de la estructura organizativa de la Federación Obrera Marítima (F.O.M.), gracias a la cual lograron romper la condición de cuasi aislamiento de Entre Ríos. En este contexto, se estableció un vínculo entre los militantes entrerrianos con la central nacional de origen sindicalista. Primero con la Federación Obrera Regional Argentina (F.O.R.A. IXoํ) ${ }^{2}$, luego la Unión Sindical Argentina (U.S.A.), más tarde la Confederación General del Trabajo (C.G.T.) para volver a la U.S.A. a mediados de los treinta cuando se produjo la ruptura de la C.G.T., siempre mediados por la F.O.M.

El vínculo descripto entre los gremialistas entrerrianos y la central nacional respondía a una estrategia de la F.O.R.A. que buscó la extensión de la organización sindical. Más allá de las declaraciones programáticas sobre la necesidad de una organización revolucionaria, los sindicalistas practicaron un pragmatismo dirigido a crear nuevos sindicatos y obtener mejoras, negociando con el Estado y los patrones. Motivo que generó la necesidad

${ }^{1}$ La Protesta Humana, Buenos Aires, 05-04-1902, p.3. La Protesta Humana, 19-041902, p.3. La Unión Obrera, Buenos Aires, 23-09-1905. Confederación, órgano de la Confederación Obrera de la Región Argentina, Buenos Aires, marzo, 1910. Ver: Leyes, 2021.

${ }^{2}$ En 1915 se produce el congreso de unidad que quita la cláusula que recomendaba el comunismo-anárquico como base de la organización sindical, hecho que motivó la ruptura entre anarquistas que mantenían aquella premisa, llamados F.O.R.A. del oo Congreso, anarquista y la F.O.R.A. IXo Congreso, sindicalista. Nos referimos a F.O.R.A. hablamos de la sindicalista. 
de ampliar la organización gremial para obtener mayor poder de negociación (Sartelli, 2020).

Por este motivo, desde 1917, comenzaron a llegar los primeros delegados a la provincia de Entre Ríos; tras viajes por los grandes ríos Paraná y Uruguay, realizaron asambleas y constituyeron sindicatos. Hechos que determinaron un fuerte incremento de la conflictividad obrera en forma de huelgas, boicots y enfrentamiento que aumentaron los niveles de confrontación hasta fines de 1920, cuando la burguesía pasó a la ofensiva y terminó con la destrucción de las organizaciones ${ }^{3}$.

El resultado de estos sucesos de la lucha de clases fue una gran derrota para los trabajadores organizados y condujo a un reflujo que duró por lo menos un quinquenio. La profundidad del reflujo se puede medir en que, para 1924, nada más que once sindicatos cotizaban para la Unión Sindical Argentina -heredera de la F.O.R.A. sindicalista- y el número de huelgas cayó a mínimos. Tan es así que, en 1926, no se registró ningún conflicto y solo existían cuatro sindicatos. (Unión Sindical Argentina, 1924, pp. 18, 63; Unión Sindical Argentina, 1926, pp. 43-45)

Hacia 1927 la organización fue relanzada, pero las organizaciones obreras necesitaron en un comienzo ayuda del exterior provincial, aunque pronto surgieron militantes locales, herederos del ciclo anterior, que tomaron en sus manos la organización gremial y concretaron el viejo proyecto de la constitución de una central obrera provincial. Durante este periodo de crecimiento endógeno, la organización obrera alcanzó una gran extensión por todo el territorio provincial y el número de sindicatos activos se elevó gracias al método de las giras (Kabat y Leyes, 2018, pp.1-20).

En este sentido, las giras se nos presentan, en términos históricos, como un emergente del crecimiento obrero. Cada vez que el movimiento obrero nacional comenzaba una etapa ascendente, aparecía la gira entre sus prioridades y seguido a la gira, un nuevo ciclo de conflictividad laboral. Las giras de organización tuvieron una importancia meridiana para el

\footnotetext{
${ }^{3}$ Desde el mes de diciembre de 1920 comenzó una fuerte ofensiva estatal por la vía de la represión policial y de los patrones por intermedio de la Liga Patriótica Argentina que destruyó la organización sindical. Los momentos más álgidos fueron los denominados sucesos de Villaguay de febrero de 1921 y la masacre de Gualeguaychú, el primero de mayo del mismo año. Ver: McGee Deutsch, 2003.
} 
movimiento obrero, hecho que no pasaría desapercibido para la historiografía. Omitiendo en este caso a los militantes historiadores que referenciaron las giras (Marotta, 1961; Oddone, 1975), la historiografía académica ubicó, desde los trabajos pioneros de Ansaldi y Sartelli (1993a), a las giras en un lugar destacado de la historia obrera. Los autores observaron el crecimiento de la organización gremial entrerriana desde 1918 a 1921 a partir de la militancia del sindicato marítimo y la participación de algunos "conferencistas" 4 por diversos parajes rurales. Asimismo, estos trabajos, a pesar de su carácter descriptivo, demuestran la conformación de "polos sindicales" en ciudades como Gualeguaychú e indican la desaparición parcial del movimiento obrero luego de las grandes represiones de 1921. En esa misma colección se publicó un artículo de Sartelli con el sugerente título de Rehacer todo lo destruido (Sartelli, 1993b, T. III). En él se destacan las giras por toda la pampa húmeda en los años treinta y se reconoce la importancia para Entre Ríos en particular. Un último punto sobre estos trabajos precursores, ambas obras muestran los dos momentos de mayor conflictividad, que, con pequeños ajustes cronológicos, nos facilita comprender el contexto de las giras.

Otro de los trabajos que dio cuenta de las giras fue el de Gilbert y Balsechi (2008) quienes, en la reconstrucción de los primeros sindicatos de Entre Ríos, recordaron a las giras de la década del veinte (pp.42-43). En 2009 se publicó el trabajo que sintetizó años de investigaciones de Adrián Ascolani (2009), quien analizó el ambiente pampeano, aunque no aportó material nuevo para la reconstrucción de las giras. También en 2009 se publicó un trabajo exclusivo sobre el tema para Entre Ríos (Leyes, 2009), que confirmaba la importancia de dichas giras para la creación de nuevos sindicatos en el periodo 1917-1921. En él se logró diferenciar la naturaleza de los recorridos y conceptualizó un modelo tipológico de las giras, elementos que se incorporan en el trabajo actual. Años después Díaz (2014), con sutiles parecidos al trabajo de Leyes $(2009)^{5}$, desarrolló las giras

\footnotetext{
${ }^{4}$ La denominación conferencista es errónea para el caso. Dado que el conferencista es un propagandista y no necesariamente un organizador.

${ }^{5}$ El trabajo de Díaz es titulado "Las giras sindicales como instrumento de construcción del movimiento obrero. La FORA en Entre Ríos", el publicado por Leyes: "La estrategia de sindicalización de la F.O.R.A. del IXo en el oriente entrerriano". El primero toma el recorte de 1918-1921, el de Leyes 1917-1921. Finalmente, la publicación de Díaz no cita el aporte previo de Leyes, con el cual necesariamente tenía dialogo.
} 
por el interior entrerriano a través del recorrido del sindicalista Ramón Suárez -verdadero sujeto del artículo- del cual el autor es biógrafo (Díaz, 2008 y 2009).

Si bien el territorio de estudio de este artículo es la provincia de Entre Ríos, no fue la única región que se benefició por la metodología de las giras de organización. Existen trabajos que muestran las giras en La Pampa (Etchenique, 2011), en el oeste bonaerense (Ascolani, 2009; Sartelli, 1993a y 1993b), en Córdoba (Mastrángelo, 2011). Fuera de la pampa húmeda, en el caso del Alto Valle del Río Negro (Etchenique y Scandizzo, 2001), en Tucumán y Santiago del Estero (Climent y Mendes Diz, 1993. Guzmán y Héctor Daniel 2013) o el por entonces territorio de Misiones (Martínez Chas, 2009).

Este breve repaso da cuenta de un territorio que se ha estudiado, pero que necesita una explicación más profunda. Estos procesos de organización no deberían ser tomados de manera aislada y superficial, ya que nos permitirá comprender el grado de desarrollo de la organización sindical a escala nacional y contrastar con la opinión de Juan Carlos Torre, para quien, recién con el peronismo se puede hablar de un "movimiento sindical nacional" (Torre, 2011, p. 59). Por lo tanto, comenzar por un territorio tan particular como el entrerriano -una provincia pampeana y marginal, con una condición cuasi insular- nos puede acercar a conclusiones más complejas que expliquen la incorporación de nuevos contingentes de obreros organizados dentro del capitalismo, que alcanzaron una nueva etapa en la conciencia de clase, reconocieron su lugar dentro del sistema y crearon una fuerza organizada de acuerdo a sus intereses económicos-corporativos (Gramsci, 2003, p. 57).

Respecto de este punto, demostraremos el vínculo entre las giras de organización de sindicatos y las huelgas ya que el objetivo de mejorar la situación de los obreros no eran aceptadas por los patrones y aquellos debieron, a fuerza de conflicto, torcer la intransigencia patronal. Esta relación permite comprender, además, la relación existente entre la organización obrera y el proceso de autoconocimiento de la clase obrera

Nuestra hipótesis de trabajo es que, en territorios con una alta dispersión demográfica, asociados a la producción agrícola y falta de militancia estable, es necesaria la intervención de elementos externos para comenzar fundar gremios (periodo de organización exógeno, 1917-1922). Asimismo, 
demostraremos que a pesar de la fuerte represión que sufrieron estos noveles sindicatos, sus cimientes no fueron removidas y pronto nacieron nuevos gremios sobre las ruinas de los destruidos, esta vez fundados por militantes locales que habían adquirido experiencia militante en el periodo inicial (periodo de organización endógena, 1927-1939). Es decir, después de un proceso de organización truncado por la represión, el movimiento obrero entrerriano se creó con relativa independencia de los militantes nacionales.

Por ello, nuestros objetivos de trabajo son tres, por un lado, reconstruir las diferentes etapas de la organización del movimiento obrero entrerriano a partir de las giras de organización como momento destacado del crecimiento sindical, en segundo lugar, mostrar el vínculo entre las giras y los conflictos obreros, relevados en forma de huelgas. En tercer lugar, demostrar que la persistencia ideológica del sindicalismo respondió principalmente a la continuidad del vínculo entre las centrales nacionales y los sindicatos locales.

El recorte temporal elegido se justifica por el comienzo y fin de las giras en la provincia de Entre Ríos. Presentamos un relevamiento que representa en forma de gráficos y mapas los resultados obtenidos entre 1917 a 1939, con la sola omisión de cuatro años de reflujo (1923-1926),

Para nuestro trabajo nos basamos en una variedad de fuentes, en especial periódicos de las centrales obreras de tendencia sindicalista. También utilizamos medios gráficos comerciales, material estadístico del Estado y fuentes inéditas, pertenecientes al acervo documental del Instituto Jauretche de la CGT en la ciudad de Buenos Aires y fuentes gremiales del Centro de Documentación e Investigación de la Cultura de Izquierdas (CEDINCI).

\section{La respuesta a una provincia agraria y dispersa con un movimiento obrero frágil y pauperizado}

La iniciativa de las giras permitió a los militantes sindicales superar una serie de obstáculos estructurales que imponía el territorio: la dispersión geográfica, la estacionalidad del trabajo agrario, la desocupación, la formación de un proletariado llamativamente pobre y la dificultad de consolidar una estructura gremial permanente en particular en el ámbito rural. En síntesis, la estructura agraria de la provincia generó una gran dispersión demográfica y laboral que no permitió el desarrollo de cuadros 
sindicales unificados, rodeados de trabajadores pobres y potencialmente desocupados. Tarea que los obreros intentaron revertir con las giras.

Hacia 1914, Entre Ríos, con una población de más de 425 mil personas, contaba con solo 17 poblados de más de 2.000 habitantes. Los habitantes por kilómetro cuadrado eran 5,7 y se calculaba que el $61,3 \%$ de población era rural. (República Argentina, 1916, T. I, pp. 108 y T. II, p.249. República Argentina, 1917, T. IV, pp. 469-475). Si tomamos las estadísticas de la provincia de Entre Ríos a mitad del recorte de nuestro estudio (1931), la población total se calculaba en 684.967 habitantes, de los cuales 61,9\% vivía en el ámbito rural. (Entre Ríos. Ministerio de Gobierno. Dirección General de Estadística, 1932) Para 1947, con un crecimiento poblacional del $85 \%$ con respecto al Censo Nacional de 1914, eran 30 las ciudades de más de 2.000 habitantes, pero aún poseía una densidad de 10,7 personas por kilómetro cuadrado y apenas el $50,1 \%$ de su población era urbana. (República Argentina. Ministerio de Asuntos técnicos, 1949, pp. 227, 232; 662-670)

El material estadístico no deja duda de la dispersión demográfica y la falta de una gran ciudad de gravitación, como podían ser los casos de las capitales y provincias de Tucumán, Mendoza o Córdoba; o el caso de Rosario en la provincia de Santa Fe. Por este motivo, constituir el movimiento obrero en Entre Ríos implicó superar la dispersión demográfica.

Asociado a la dispersión propia de la estructura agraria capitalista, existía otro problema de importancia: la estacionalidad del trabajo. Se vivían periodos de mucho trabajo, como eran la trilla de los cereales o la faena los establecimientos de procesamiento de carne, donde se concentraban a obreros de diversas localidades, incluso, trabajadores correntinos y uruguayos; para luego ser repelidos por el sistema que los obligaba a la desocupación o bien a continuar una diáspora laboral. Así fue que esta masa de obreros descalificados, caracterizados como una "infantería ligera del capital" (Marx, 2001, T.I, pp. 544-545) se movían de un lugar a otro, alternado por periodos de desocupación.

Esta situación de desocupación flotante se hizo más acuciante en la segunda mitad de la década del veinte y en los albores de la década del treinta, cuando el aumento de la mecanización en el agro y en la industria, la caída de los precios agrarios y el desplome de las exportaciones primarias en el contexto de la crisis de 1929, dio por resultado una 
desocupación permanente. Se produjo un cambio sustantivo en la estructura de la clase obrera, desde la desocupación flotante a la denominada sobrepoblación obrera (Kabat, 2009). Esta desocupación permanente se calculó en torno a veinte mil trabajadores, número que asciende si consideramos el peso que tuvo la migración desde la provincia a otras donde hubiera ocupación. Por lo cual, cualquier cálculo debería considerar este número indefinido de trabajadores entrerrianos que dejaron la provincia y que se estima en más de 125 mil personas dentro del periodo de estudio de este artículo (Leyes, 2016 y 2018).

A consecuencia de la desocupación como un elemento estructural, la sobreoferta de fuerza de trabajo permitió a la burguesía local ofrecer salarios bajos. Así que el proletariado entrerriano era particularmente pobre frente a sus pares de otras provincias pampeanas. Los sindicalistas en gira dejaron constancia de esta situación. Por ejemplo, en 1920, Luis Lotitto decía respecto del poblado rural de Estación Urquiza:

Es una estación poco poblada. El principal trabajo que hay es de estiba y acarreo de cereales. Los estibadores y conductores de carros han formado un Sindicato Obreros de Oficios Vario, que reúne en su seno a la mayoría de los trabajadores domiciliados en este pueblo (...) El sindicato fundado en el mes de marzo ha conseguido para los trabajadores de estiba importantes ventajas. Antes trabajaban la antigua jornada de sol a sol; lograron la de 9 horas y se preparan para, en la próxima cosecha, obtener la jornada de 8 horas. Se les pagaba antes cuatro pesos en verano, en la época de mayor trabajo; luego en invierno, además de sufrir el obrero la desocupación, los escasos días que se trabajaba, apenas percibía el jornal de tres pesos $(\ldots)^{6}$.

A mediados de 1929, un delegado de la Unión Sindical Argentina, hacía referencias a las condiciones de los trabajadores del extremo noroeste provincial:

Entre los trabajadores de la ciudad de La Paz (Entre Ríos) se han iniciado trabajos tendientes a reorganizar sus cuadros sindicales, destruidos a raíz de la violenta reacción producida años atrás en la provincia de Entre Ríos. Desapareciendo la organización, las condiciones de vida de los obreros de todos los oficios e industrias sufrieron un rudo golpe, llegando en los momentos actuales a un

${ }^{6}$ Semanario La Organización Obrera (L.O.O.), Buenos Aires, 07-08-1920, p. 3. 
grado inconcebible de miseria. En general, y en todos los órdenes, son los obreros escandalosamente explotados, cosa que resalta a primera vista cuando se contempla el aspecto mísero de los niños proletarios (...) Las familias obreras viven en repugnante promiscuidad en chozas miserables (...) Como un ejemplo de lo que decimos, citaremos el jornal de los obreros en algunos oficios: los estibadores -tanto en el puerto de La Paz como en Puerto Márquez. Que es una localidad vecina- ganan $4 \$$ por día y están obligados a proveerse en las casas de los patrones (Groisman y Cía. Y Tellarini Hnos.) que como se comprenderá fácilmente, no lo hacen con el propósito de beneficiar a los obreros $(\ldots)^{7}$.

Para que los salarios nominales tengan un sentido comparativo se debe constar que para 1919-1920, en la región cerealera de la provincia de Buenos Aires, los estibadores cobraban en promedio \$8.8, mientras en Entre Ríos no llega a la mitad (Sartelli, 1993a, t. I, p. 70). En tanto, la misma región bonaerense contra los salarios entrerrianos, para 1928, los estibadores tenían jornales de $\$ 8$ por ocho horas laborales, más el pago de $\$ 1.50$ por horas extras (Sartelli, 1993b, t. III, p.245). Esto explica por qué el sindicalista en gira se asombró de salarios de \$4 en los obreros de La Paz, con el agregado de la obligación de comprar en los negocios de sus mismos patrones. La represión, la desocupación y la desorganización mantenían a los trabajadores entrerrianos en condiciones paupérrimas frente al resto del proletariado pampeano.

Ahora bien, la situación de desocupación -y los problemas con ella asociada- dificultaban la organización de los trabajadores. Los obreros, cuando no estaban en movimiento, estaban desocupados y casi siempre dispuestos a trabajar por cualquier sueldo. Por lo tanto, la organización obrera se veía vacía de militantes activos o con una masa de desocupados que empujarían los salarios a la baja. Por este motivo era que, en los momentos de cosechas y especialmente la trilla, eran momentos álgidos de las luchas. Los patrones demandaban trabajadores, y los trabajadores se encontraban en un lugar concreto que permitía su organización. Aquí y allá se fundaban sindicatos que desaparecían a la primera huelga pérdida o cuando terminaba la cosecha. Por resultado, hasta mediados de la década del treinta lo que existe es un movimiento obrero débil con una baja institucionalización (Pianetto, 1983. Sartelli, 1993a, T. II, p.238, Kabat y Leyes, 2018).

${ }^{7}$ Semanario Bandera Proletaria, (B.P.), Buenos Aires, 20-07-1929, p.3. 
Este escenario generó un último obstáculo, la falta de cuadros sindicales permanentes. De allí que, en provincias con una gran dispersión geográfica, agraria y sin una ciudad sobre la que gravite la vida política, sindical o económica, hace falta para la organización un "catalizador externo". Es decir, una presencia externa -normalmente una central gremial nacional que envíe sus delegados- al medio que unifique a todos los militantes dispersos. Una vez saldados estos problemas, estaremos en presencia de un "polo sindical" que puede continuar la tarea organizativa con independencia del centro de agitación nacional.

\section{Catalizadores externos: la organización exógena y la importancia de los vínculos extra-provinciales, 1917-1922}

Sobre las bases materiales antes dichas -dispersión, desocupación y falta de cuadros gremiales- los militantes encontraron en las giras un método para desarrollar los sindicatos. La iniciativa de las giras se sistematizó a partir del compromiso asumido por los sindicalistas en el histórico IXo Congreso de la F.O.R.A. de $1915^{8}$.

El funcionamiento inicial era relativamente sencillo. El delegado recorría los grandes ríos que envuelven a la provincia mesopotámica, se contactaba con trabajadores o militantes espontáneos, una vez establecido el nexo se amplía el contacto con otros trabajadores del mismo oficio, pasado el protocolo burocrático de llamar a una asamblea constitutiva, se procedía a escribir y presentar un pliego de condiciones y comenzar la lucha por mejoras. (Leyes, 2009: 38) El paso siguiente era el agrupamiento en federaciones locales, es decir, unificar a los obreros de una misma localidad dentro de Sindicatos de oficios varios (S.O.V.) o gremios particulares, en función de la cantidad de afiliados de un mismo oficio. Así nacían las denominadas uniones "departamentales" o "comarcales". Este impulso organizativo se explicitó en los estatutos de la F.O.R.A. desde 1920:

(...) las ventajas que ofrecen a la organización en general estas entidades departamentales son de un valor inestimadas. Los núcleos sindicales concentrados en su seno permiten el empleo común de esfuerzos y recursos superiores a los que se tienen cuando se viven

${ }^{8}$ L.O.O., 07-12-1918, p. 4. 
aislados; facilitan la coordinación de sus actividades en una acción común determinando, a la vez, una mayor extensión del radio de influencia de la organización sindical $(. . .)^{9}$.

Usaban el caso de Gualeguaychú, como ejemplo, para fundamentar la resolución ${ }^{10}$.

La provincia de Entre Ríos recibió a su primer delegado entre diciembre de 1917 y enero de 1918. Fue Simón Larroche, delegado de la F.O.M., en la costa del río Uruguay, quien recorrió Concordia, Salto (R.O.U.), Colón y Concepción del Uruguay. En todas ellas logró conformar sindicatos. Sobre la costa del Paraná, sucedió algo parecido en julio de 1918 cuando Sebastián Marotta viajó a Paraná, Bajada Grande y Victoria ${ }^{11}$. El proceso coincidió con las denominadas giras fluviales (Leyes, 2009).

De acuerdo con este plan, durante el año 1919 las giras continuaron y se planificó una fuerte gira por el interior del país, Entre Ríos fue uno de los territorios más favorecidos ${ }^{12}$. Se recorrieron los pueblos más alejados en lo que denominamos giras ferroviarias que, como su nombre indica, no serán por los grandes ríos, sino por los poblados a la vera del tendido ferroviario ${ }^{13}$.

Entre las consecuencias de este periodo se destaca la consolidación del primer polo sindical de la provincia en la ciudad de Gualeguaychú. A mediados de 1919 esta ciudad se convirtió en el principal bastión del movimiento obrero provincial, hecho reconocido por los militantes nacionales quienes, con cierta paternidad sobre los organismos obreros locales, decían: "(...) la F.O.R.A. fue la que por intermedio de sus delegados trajo la buena nueva de la organización sindical obrera a estos parajes". Señalaban que un año y medio atrás sólo existían dos sindicatos -

${ }^{9}$ L.O.O., 01-05-1920, p.2.

${ }^{10}$ L.O.O., 12-06-1920, p.2.

${ }^{11}$ L.O.O., 19-01-1918. p. 4. L.O.O., 26-01-1918. p. 4. L.O.O., 02-02-1918. p. 2. L.O.O., 10-08-1918, p.1. L.O.O., 12-10-1918, p.2.

${ }^{12}$ L.O.O., 20-12-1919, p.3. Ver "Datos de la gira de propaganda a cargo del camarada Ramón Suarez", 15-05-1920, Buenos Aires, Copiador de Cartas F.O.R.A. IXo, (02-12-1919--31-01-1920), Folio 721.

${ }^{13} \mathrm{El}$ territorio provincial no fue solo recorrido por el ferrocarril, encontramos referencias de delegados que viajaban distancias medias a caballos, en sulkys y, llegado a los años treinta, en camión. Aunque el ferrocarril continuó siendo el medio predominante y de mayor extensión. 
estibadores y Ferroviarios de Ibicuy-. Para marzo de 1920, ocho sindicatos ya agrupaban al $70 \%$ de los obreros. Los autores de la nota citan dos giras de organización de Daniel Alvarado, dos visitas de Ramón Suarez, también la participación de E. Mársico y Bartolomé Senra Pacheco ${ }^{14}$. Este listado se limitaba a Gualeguaychú, que era denominada por Luis Lotito -un destacado militante nacional de la corriente sindicalista- como una "pequeña Buenos Aires obrera" por su ambiente sindical. Remarcaba: “(...) una buena parte se debe a la atención que la F.O.R.A. ha prestado a esta localidad. La visita repetida de sus delegados ayudó mucho a los voluntariosos militantes de Gualeguaychú. Si se pudiera hacerse otro tanto con cada ciudad, se obtendría, lógicamente, el mismo resultado"15. Lotito no era el único que veía el valor y los resultados de las giras en el territorio entrerriano. Francisco Docal, delegado de la F.O.R.A. en el sudoeste de la provincia en 1920, afirmó:

Creo que el movimiento sindical entrerriano se encuentra en las mejores condiciones de progreso, pero entiendo que precisamente por tratarse de movimientos nuevos deben merecer del Consejo la mayor atención posible. No quiero decir con esto que el movimiento de esa provincia no haya preocupado, con especialidad a los compañeros, pero entiendo debe persistirse en la labor sin descanso. Hay mucho que trillar en ese movimiento para conseguir la formación de núcleos (...) Para esto, nada mejor que proseguir las giras, especialmente en las épocas de trabajo ${ }^{16}$.

Finalmente, los obreros de Gualeguaychú lograron enviar delegados propios a otras localidades vecinas -destaco aquí la labor de la obrera María Bella Amestoy Carrera, organizadora de sindicatos de oficios varios femeninos-, al igual que los trabajadores de Concepción del Uruguay, quienes una vez constituida la Unión Obrera Departamental (U.O.D.), organizaron a los obreros de los pueblos de su área de influencia ${ }^{17}$. Denominamos a estas medidas como giras regionales, enfatizando la iniciativa de los obreros locales (Leyes, 2009, p.40.). Tienen una importancia vital porque muestran la madurez de los polos sindicales y el despegue del movimiento obrero endógeno y autónomo.

${ }^{14}$ L.O.O., 03-04-1920, p. 1.

${ }^{15}$ L.O.O., $14-08-1920$, p.3

${ }^{16}$ L.O.O., 06-11-1920, p.2

${ }^{17}$ L.O.O., 06-03-1920, p.4. L.O.O., 01-01-1921, p.2. L.O.O., 10-04-1920, p.4. 
La coronación de la organización local fue el intento de creación de una federación provincial, en enero de 1921, con la presencia de 34 sindicatos, 4 federaciones locales y del dirigente nacional sindicalista Sebastián Marotta. Pero la represión estatal-patronal se profundizó algunas semanas después, hundiendo a buena parte de las organizaciones locales y con ellas, a la Federación Obrera de la Provincia de Entre Ríos. La institución provincial tenía entre sus primeros objetivos enviar delegados a las localidades donde no existieran sindicatos ${ }^{18}$. Es decir, era una etapa superior de las giras regionales, organizadas de modo centralizado, pero la acción se truncó por la fuerte represión que inició una etapa de reflujo.

Adán lbañez, delegado de la F.O.R.A., se refería a la situación en mayo de 1921:

El proletariado de la provincia de Entre Ríos atraviesa un momento especial de crítica situación. Situación que el Consejo Federal no debe descuidar un solo momento, que nuestros hermanos en aquella provincia, recibieron nuestra cooperación para emprender nuevas luchas en procura de los derechos sindicales. Derechos hoy desconocidos por los zánganos de la colmena social. Es preciso que Entre Ríos vuelva a ser lo que fue, esto es, un baluarte de organización sindical ${ }^{19}$.

Por su parte, el delegado Villacampa indicó que el declive organizativo había comenzado en la profunda dependencia de la F.O.M. Señaló el caso de Gualeguaychú, que durante una huelga que los marítimos no pudieron asistir, los sindicatos locales fracasaron en sostener el conflicto por sus propias fuerzas. El delegado objetó a los trabajadores entrerrianos no responder al llamado de huelga general por los hechos represivos. También argumentó que no se podía dar ayuda a quien lo pidiera sin un plan establecido y recriminó la falta de pago de las cotizaciones y la creación de un fondo para los meses invernales. Finalizó diciendo: "Estos puntos, de todos conocidos, que dejo señalado, no es de hoy que tenerlos en cuenta;

${ }^{18}$ L.O.O., 22-01-1921, p.2. Vespertino El Diario, Paraná, 20-01-1921. Diario El Argentino, Gualeguaychú, 16-01-1921, p.2, El Argentino, 14-01-1921, p.2. El Argentino, 15-01-1921, p.2.

${ }^{19}$ L.O.O., 28-05-1921, p.3. 
correspondía haberlos escuchado hace un año, cuando los veníamos exponiendo" 20 .

Un obrero de lbicuy, en tono de respuesta a Villacampa, escribió a La Organización Obrera. Indicó tres elementos para entender el reflujo que comenzaba: la desocupación, la represión y la falta de experiencia. Afirmó: "No hay 'desastre', estamos en un compás de espera; y confiemos sin pecar de optimistas, que resurgirán con más bríos y más fuertes las organizaciones sindicales para dar la revancha" 21 . Sin embargo, el reflujo fue más profundo de lo esperado.

En diciembre de 1921, cuando llegó de Diamante el delegado de la F.O.R.A. planteó la dificultad de encontrar militantes. La desmoralización y los desacuerdos personales impedían la organización de los trabajadores ${ }^{22}$. En tanto el estado de enfrentamiento con la patronal era tal que los miembros del consejo federal de la F.O.R.A. elevaron un pedido al gobernador en el que exigían garantías a los delegados ${ }^{23}$. Entre el final de 1921 y los primeros meses de 1922, delegados de la F.O.R.A. reorganizaron a los obreros de Gualeguaychú, Paraná, Diamante, Concordia, La Paz, Pueblo Brugo $^{24}$. El ciclo se cerraba con un retorno a las giras por las costas de los ríos.

\section{Polos sindicales: de la gira exógena a la gira endógena, 1927-1939}

El reflujo vivido por el proletariado se extendió por casi cinco años. En enero de 1925 se intentó lanzar una nueva campaña de reorganización desde Concepción del Uruguay. El dirigente Antonio Aguilar escribió en Bandera Proletaria una extensa nota titulada "El proletariado de Entre Ríos y las Giras de propaganda sindical"; en la que objetó que desde los tiempos de la F.O.R.A. no se hacían giras de organización en la provincia, y que la U.S.A. solamente envió delegados cuando los sindicatos locales lo solicitaron y luego volvían a la Capital Federal. Aseveró que era impostergable volver a

${ }^{20}$ L.O.O., 09-07-1921, p.2. L.O.O., 23-07-1921, p.1.

${ }^{21}$ L.O.O., 27-08-1921, p.2.

${ }^{22}$ L.O.O., 07-01-1922, p.3.

${ }^{23}$ L.O.O., 25-02-1922, p.2.

${ }^{24}$ L.O.O., 24-09-1921, p.4. L.O.O., 07-01-1922, p.3. L.O.O., 11-02-1922, p.4. L.O.O., 11-02-1922, p.4. L.O.O., 18-02-1922, p.3. 
las giras de propaganda "(...) que tantos resultados dieron a la clase obrera en los tiempos gloriosos del 1920 al 23, y que por doquiera que hoy tendamos nuestra mirada, no hemos ni siquiera vislumbrar la esperanza de que aquellos tiempos heroicos vuelvan". La nota de Aguilar era un paneo general de la desorganización imperante y finalizó con la descripción de un escenario potencial:

No obstante esta situación, en todas las localidades, desde La Paz a Concordia, por el litoral, hay grupos de compañeros, que pienso, y tengo la más firme convicción que están dispuestos a la lucha en cuanto la Unión Sindical Argentina dé el primer alerta; pero debe de darlo fuerte, cosa que a través de toda la Provincia, resuene en los oídos de esta burguesía maldita y asesina, que cada día esclaviza más y más a los trabajadores y para que sirva de aliento a los proletarios todos, que volverían por los fueron y levantaran de nuevo los aguerridos baluartes sindicales ${ }^{25}$.

La dirección de la U.S.A. tomó nota de los dichos. En ese mismo número de Bandera Proletaria se hizo un descargo. Respondieron que la organización sindical también debía correr por orden de los militantes locales: "(...) si aquellos camaradas que en otrora ponían todos sus entusiasmos a favor de un mayor acrecimiento de los sindicatos, no hacen nada y lo dejan todo al arbitrio del C.C. [Comité Central] las jiras no habrán de obtener el resultado apetecido"26. Durante el Segundo Congreso de la U.S.A., en 1926, el debate de las giras volvió al ruedo y se incluyó entre sus resoluciones. Las giras se ordenarían de acuerdo a un plan de localidades prioritarias y agitarían el encarecimiento y la desocupación (Marotta, 1960, p. 218; Unión Sindical Argentina, 1926).

En junio de 1927 llegó el primer delegado desde la Capital Federal a Entre Ríos, José Paz, quién se encargó de armar el sindicato de oficios varios de Concepción del Uruguay. Poco tiempo después, militantes locales fundaron el sindicato de los aguateros. Algo similar ocurrió en 1928 en Paraná, a partir de una huelga de los gastronómicos que contó con la ayuda de los albañiles de Santa Fe. En abril de ese mismo año, López Coaraza, un delegado de la U.S.A. que arribó a Concepción del Uruguay, reorganizó el gremio de panaderos, el S.O.V. local y el de Colón. Por otra parte, se llamó a los miembros de la U.O.D. a restablecer al S.O.V. de Rosario del Tala,

${ }^{25}$ B.P., 03-01-1925, p.3.

${ }^{26}$ B.P., 03-01-1925, p.3. 
tarea lograda por Juan Balsechi ${ }^{27}$. También Manuel Morales, un delegado espontáneo de visita por cuestiones familiares en Gualeguaychú, se dio a la tarea de refundar el S.O.V. de ese lugar con ayuda de los viejos miembros locales. También los estibadores de Diamante fueron organizados por militantes de Santa $\mathrm{Fe}^{28}$.

En 1929 encontramos al militante de la F.O.M., Juan Elcura, de gira por el río Uruguay con destino a Concordia. Decía al respecto Bandera Proletaria: "Merece destacarse la actividad que despliegan los camaradas de C. del Uruguay, los cuales no se limitan a trabajar por la organización local, sino que tratan de llevar sus beneficios a los pueblos vecinos" 29 . Los primeros meses de 1930 el eje de organización endógena se establece en la costa del río Paraná y encontramos a los estibadores de Diamante organizando obreros en su región ${ }^{30}$. Justamente un obrero anarquista de ese poblado, Ángel Borda, relató cómo se realizaban aquellas giras por el interior provincial:

(...) si llegaba a un horno de ladrillos, pedía un molde y hacía un barato [trabajo sin pago] al que estaba trabajando para que descansara y se fumara un cigarrillo. Después me lavaba y conversaba con los obreros sobre la necesidad de organizarse. Finalmente tuvimos éxitos (...) (Borda, 1986, pp.34-35.)

La crisis económica de 1930, la represión desatada por la dictadura militar y la reorganización de las centrales sindicales más importantes en torno a la Confederación General del Trabajo (C.G.T.) llevaron a un impasse de las giras por la provincia. No tenemos noticias hasta 1932, cuando Asociación de Trabajadores del Estado dispuso a uno de sus cuadros, Domingo Heredia, a la tarea de mejorar la organización de varias seccionales del interior, entre ellas las entrerrianas de Paraná, Diamante y Concepción del

\footnotetext{
${ }^{27}$ Balsechi fue el principal cuadro sindical de la provincia de Entre Ríos desde fines de la década del veinte hasta el peronismo. En este último período, fue encarcelado repetidas veces y terminó con su exilio en el Uruguay. Ver: Leyes, 2017, pp. 132150.

${ }^{28} B P, 10-09-1927 . B P, 07-01-1928 . B P, 28-01-1928 . B P, 04-02-1928 . B P, 18-02-$ 1928. $B P, 19-05-1928$. BP, 15-09-1928. BP, 03-11-1928. BP, 28-09-1929.

${ }^{29} B P$, 23-03-1929, p.1.

${ }^{30} B P, 25-01-1930$. p 1. $B P, 15-02-1930$, p. 1
} 
Uruguay ${ }^{31}$. En abril de aquel año se agremiaron los estibadores de Paraná con la participación de obreros de Diamante, Santa Fe y Concepción del Uruguay ${ }^{32}$. Finalmente, en julio de 1932, la C.G.T. envía a dos delegados. Uno de ellos era un miembro de la Federación Ferroviaria y el otro un conocido de la provincia, Adán Ibáñez ${ }^{33}$. Visitaron Paraná, La Paz, Strobel y Basavilbaso ${ }^{34}$.

Como vemos, se inició la reorganización con rasgos de continuidad con el periodo anterior. La particularidad es que esta vez se buscó a los militantes que habían dirigido los sindicatos durante el periodo 1917-1922, quienes comenzaran a replicar a escala regional el mismo proceso de formación de sindicatos. Así es que el modelo de crecimiento se presentó en forma mixta, entre la táctica anterior, dependiente de las fuerzas exógenas de la provincia y el pasaje al desarrollo autónomo. Esta etapa intermedia se desarrolló entre 1927-1932 aproximadamente.

En septiembre de 1932 se produjo un quiebre con el periodo anterior por la creación de la Unión Obrera de la Provincia de Entre Ríos (U.O.P.E.R.), resultado de la suma de los dos polos sindicales provinciales más importantes: Diamante y Concepción del Uruguay. Diecinueve sindicatos participaron del acto fundacional y otros diez pidieron su incorporación a las pocas semanas. Entre las primeras medidas de la U.O.P.E.R. se estableció que los militantes uruguayenses Juan Balsechi (panadero) y Martín García (F.O.M.) recorrieran los poblados entre Concepción del Uruguay y Diamante de acuerdo con el tendido del ferrocarril Central entrerriano ${ }^{35}$. Decían en una circular publicada en el Boletín de la CGT:

La UOP mantiene el mismo propósito del año pasado de levantar los cuadros sindicales en la Provincia paralizado por el fracaso de la cosecha; pero tenemos el más firme convencimiento que los camaradas de las diversas localidades que supieran responder al llamado de la UOP, habrán sabido conservar su espíritu de lucha y

\footnotetext{
${ }^{31}$ Semanario Boletín de la Confederación General del Trabajo, (BCGT), Buenos Aires, 15-01-1932, p.4.

${ }^{32}$ El Despertar, Concepción del Uruguay, abril, 1932, p.5.

${ }^{33}$ El histórico militante de la F.O.R.A. y delegado por el Concejo Federal de aquella central, en varias oportunidades, a Entre Ríos durante la oleada anterior, en ese momento residía en Paraná. BCGT, 25-01-1934, p.4.

${ }^{34} B C G T, 25-08-1932$, p.5.

${ }^{35} B C G T, 25-11-1932$, p.3.
} 
sacrificio demostrando en otras oportunidades y no creemos tampoco que la falta de trabajo y penurias sufridas, haya sido motivo para renegar del anhelo de mejoramiento social.

Planteaban finalmente que las perspectivas de reconstitución eran halagadoras. Para ello presentaron un plan de trabajo: reunir a los trabajadores y conformar una comisión reorganizadora, escribir un pliego de demandas que debía ser remitido primero a la U.O.P. para su consideración, se tenían que adherir a la U.O.P. y a la C.G.T., se obligaba a remitir dinero para el sello del sindicato $y$, por último, se debían comprometer a fundar gremios en las localidades cercanas donde no existiesen ${ }^{36}$.

La segunda gira promovida por la U.O.P.E.R. se realizó entre noviembre de 1933 y febrero de $1934^{37}$. El recorrido siguió varias líneas ferroviarias y caminos por el norte y sur de la provincia. Decía el periódico de la CGT:

Con todo éxito viene realizando una campaña de organización sindical por todo el territorio de la provincia el Consejo del a U.O.P., aprovechando la situación de miseria por que atraviesan los trabajadores a consecuencia de la crisis reinante, la que es utilizada por los capitalistas para pagar salario de hambre a cambio de tareas realmente penosas (...) Con fecha 9 del corriente [noviembre] se inició la primera jira que abarcó un recorrido de mil doscientos kilómetros desde Uruguay hasta Nogoyá y desde ésta a Seguí, continuando hasta Federal, visitándose Puerto Brugo, Curtiembre y Cerrito, en cuyas localidades se constituyeron sus respectivos sindicatos. La línea del F.C. del E. desde Seguí hasta Villa Federal fue visitada dos veces. De regreso, se organizó el sindicato de General Campos. La segunda jira se inició el 20 del actual por la línea a Gualeguay y centro, hasta Hernández y Maciá, Victoria e Ibicuy. La tercera se inició el 21 a los efectos de visitar Clarita, Jubileo, S. Salvador, Barú, Ubajay, San Antonio y otras localidades cercanas.

${ }^{36} B C G T, 25-10-1933$, p.2.

${ }^{37} B C G T, 25-12-1933$, p.2.BCGT, 28-02-1934, p.1. 
Se crearon sindicatos en treinta localidades ${ }^{38}$. Los frutos de la gira no tardaron en llegar. Surgieron sindicatos donde nunca habían existido y se renacieron los que se perdieron en el reflujo de la década de 1920. En febrero de 1934 se afirmaba que la gira había alcanzado María Grande, Sosa, Tabossi, Viale, Seguí, Villa Crespo, Mansilla y Galarza. En todas ellas, los conflictos fueron resueltos favorablemente para los trabajadores. Sin embargo, no se pudo levantar viejos bastiones como Nogoyá y Victoria: "(...) no fue posible consolidar la organización por la falta de comprensión de los interesados, pero han quedado constituidos grupos de entusiastas camaradas que prosiguen sin desmayo la obra (..." $)^{\prime 39}$.

La tercera gira de la U.O.P.E.R. fue durante el verano de 1934-1935 y se desarrolló en tres direcciones, Balsechi y Pereyra tomaron la línea del Central entrerriano y luego por la línea de los Ferrocarriles del Estado hacia el norte de Entre Ríos; Gargano y Tullier se dirigieron hacia el sur, rumbo a Gualeguay y finalmente, De los Santos y Lambert se movieron dirección Concordia. De todos, el punto de partida fue Concepción de Uruguay. En abril decían que habían recorrido 5.500 kilómetros $^{40}$.

Esta experiencia produjo dos hechos de importancia. El primero, generó un ascenso de las luchas, haciendo de 1935 el año de mayor conflictividad del periodo 1927-1943 (Kabat y Leyes, 2018, pp.1-20.). El segundo, fue que se descubrió que los militantes de Diamante planeaban crear una federación provincial alternativa con los preconceptos del comunismo-anárquico, lo que determinó la expulsión de ellos de la U.O.P.E.R. y una lucha intestina que duró casi dos años. Finalmente, los obreros diamantinos desaparecieron bajo la represión estatal (Arnaiz, 1991; Leyes, 2020).

Este quiebre de la unidad obrera debilitó los sindicatos provinciales; por eso, a principios de 1938, se realizaron diversos viajes con el fin de reactivarlos en localidades como Mansilla, Nogoyá, Seguí, Clé, Colón y Gualeguaychú ${ }^{41}$.

\footnotetext{
${ }^{38}$ Se especifican: Villa Mantero, Basavilbaso, XX de Septiembre, Colón, Solá, Lucas González, Maciá, Mansilla, Galarza, Crespo, Strobel, Diamante, Paraná, Urquiza, Urdinarrain, Las Moscas, Villa Clara, Villaguay, Concordia, Domínguez, Libaros, Gualeguaychú, Santa Fe -gira de solidaridad - Tala, Racedo, Cazes, Ramírez, Victoria, la fuente indica "otras". CGT, 07-12-1934.

${ }^{39}$ BCGT, 28-02-1934, p.8.

${ }^{40}$ CGT, 30-11-1934, p.2. CGT, 07-12-1934, p.2. CGT, 19-04-1935, p.4.

${ }^{41}$ El Despertar, 1 de mayo de 1939, pp. 2 у 3.
} 
Este trabajo fue analizado en el Tercer Congreso de la U.O.P.E.R. cuando se discutió la disminución de sindicatos y se concluyó que el fracaso de la experiencia anarquista se debió a la falta de una militancia consolidada y eran los motivos más importantes del nuevo retroceso. Sin embargo, se planteó la necesidad de reorganizar los sindicatos caídos ${ }^{42}$. En agosto de 1938 comenzaron nuevas giras regionales. Los militantes de Concepción del Uruguay lograron reunir a los panaderos de Colón; igualmente hizo el S.O.V. de San Salvador con los panaderos de General Campos, y desde Rosario del Tala llegaron noticias de que los estibadores de Mansilla se habían reorganizado y preparaban pliegos de reivindicaciones para la próxima cosecha ${ }^{43}$. Decían los dirigentes de la UOPER:

La Unión Obrera Provincial, siempre, atenta y celosa de los intereses de la clase Obrera, se apresta en estos momentos a iniciar una vigorosa campaña de reorganización en toda la Provincia (...) Es necesario que todos y cada uno de nuestras organizaciones aporten su grano de arena para la bandera de la organización sindical en toda la línea del F.C. del Estado desde Crespo a Villa Federal. Los trabajadores de esta línea, saben perfectamente, que la acción de la Unión Obrera Provincial, que fecunda é eficaz en todo momento y que su obra sindical fue límpida y sana, y saben también los trabajadores, que bajo el control de la U.O.P., supieron triunfar los trabajadores de esta línea, como otras tantas organizaciones del interior (...) cumplir una nueva consigna, es decir no escatimar ningún sacrificio hasta materializar los propósitos de la Unión Obrera Provincial: ORGANIZAR AL PROLETARIADO DE ENTRE RÍOS ${ }^{44}$.

En una mirada retrospectiva, el año 1938 fue uno de los más activos en tareas de reorganización de los sindicatos caídos por las luchas de principios de 1937. El peso de la U.O.P.E.R. se consolidó e hizo extensivo a toda la provincia. En 1939 se cerró el ciclo de luchas obreras, y con él, la iniciativa de realizar nuevas giras de organización. El siguiente ciclo de ascenso organizativo será al inicio del peronismo, entre 1943-1946, y la naturaleza estatal de aquel fenómeno le dará nuevo contenido y formas.

${ }^{42}$ El Despertar, febrero de 1938, p.5.

${ }^{43} E D$, agosto de 1938.

${ }^{44} E D$, octubre de 1938. Mayúsculas en el original. 


\section{Las giras y sus resultados}

A continuación, se presentan dos cuadros que nos permiten reconocer de modo cuantitativo las consecuencias organizativas de las giras, y material cartográfico para presentar la extensión territorial de las giras y sus orígenes predominantes, según el periodo de estudio. Para ello nos basamos en los datos construidos a partir de medios periodísticos nacionales y provinciales.

Entre noviembre de 1917 y febrero de 1922 hemos contabilizado, de la mano de la F.O.R.A. IXo, la creación de ochenta y cinco sindicatos en treinta ciudades y pueblos ${ }^{45}$. El proceso de organización comenzó en noviembre de 1917 y su punto más alto fue en el año 1920. Empero, cuando nos preguntamos por la participación de los delegados externos en la creación de nuevos sindicatos, su acción asciende al $75 \%$ de los sindicatos que fueron fundados. El 25\% restante correspondió a la acción de miembros de los polos sindicales y los sindicatos que se desarrollaron de modo espontáneo.

Por otra parte, destacamos que tanto delegados de la F.O.R.A., como los militantes locales superpusieron sus giras a partir de 1920, cuando se establecieron polos sindicales que comenzaron la tarea organización sindical autónoma. Los núcleos más importantes fueron: Gualeguaychú con creces el más importante- y Victoria. Hubo otros tres núcleos sindicales que tuvieron actividad menor: Bajada Grande, Concepción del Uruguay y Villa Clara. Sin embargo, la ofensiva patronal destruyó sus cuadros y la presencia de los militantes extra-provinciales volvió a ser central entre la mitad de 1921 y los primeros meses de 1922.

Otra información que hemos agregado a la figura no 1 es el nivel de conflictividad en la provincia. También hay que enfatizar la relación estrecha entre la constitución de nuevos sindicatos y el aumento de las huelgas. Por ello el año 1920 es, además del año de mayor cantidad de fundaciones, el más conflictivo.

\footnotetext{
${ }^{45}$ Bajada Grande, Basavilbaso, Britos, Colón, Concepción, Concordia, Curtiembre, Diamante, Escriña, Estación Urquiza, Gilbert, Gualeguay, Gualeguaychú, Ibicuy, Irazusta, La Capilla, La Paz, Larroque, Nogoyá, Paraná, Parera, Pueblo Brugo, Puerto Esquina, San Salvador, Santa Elena, Urdinarrain, Victoria, Villa Clara, Villa Domínguez y Villaguay.
} 
Figura 1: Organización de sindicatos obreros en la provincia de Entre Ríos, 1917-1922

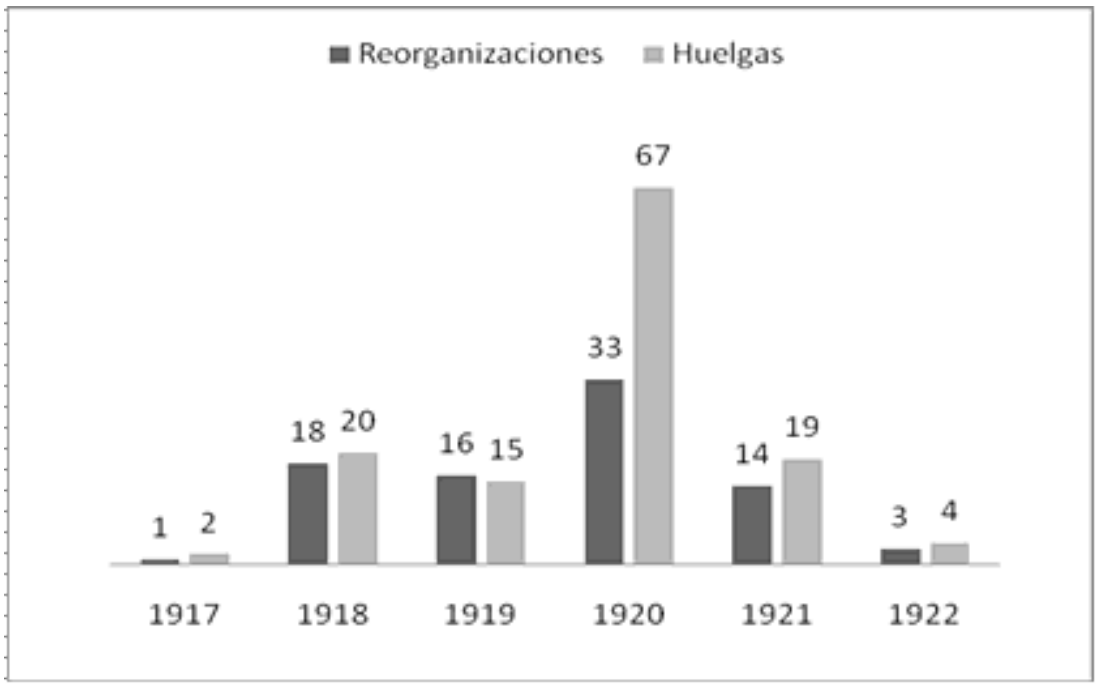

Fuentes: Elaboración propia sobre la base de los siguientes periódicos: $\mathrm{La}$ Vanguardia, Buenos Aires, órgano del Partido Socialista; La Organización Obrera, Buenos Aires, órgano de la Federación Obrera Regional Argentina, y La Protesta, Buenos Aires, periódico anarquista.

El mapa (figura 2) presenta un recorrido centrado en la costa del río Uruguay, formando un eje entre Concordia al norte e lbicuy al sur. En tanto, el interior de la provincia fue recorrida de acuerdo con las vías del ferrocarril central entrerriano y la línea Este argentino, por último, la costa del río Paraná siguió la vía fluvial. Se desataca la incidencia de la militancia extraprovincial en la organización, y en menor medida la incipiente militancia local a partir de los núcleos sindicales arraigados. 
Figura 2: Recorrido de obreros en gira según su origen local o extra-provincial. Entre Ríos, 1917-1922

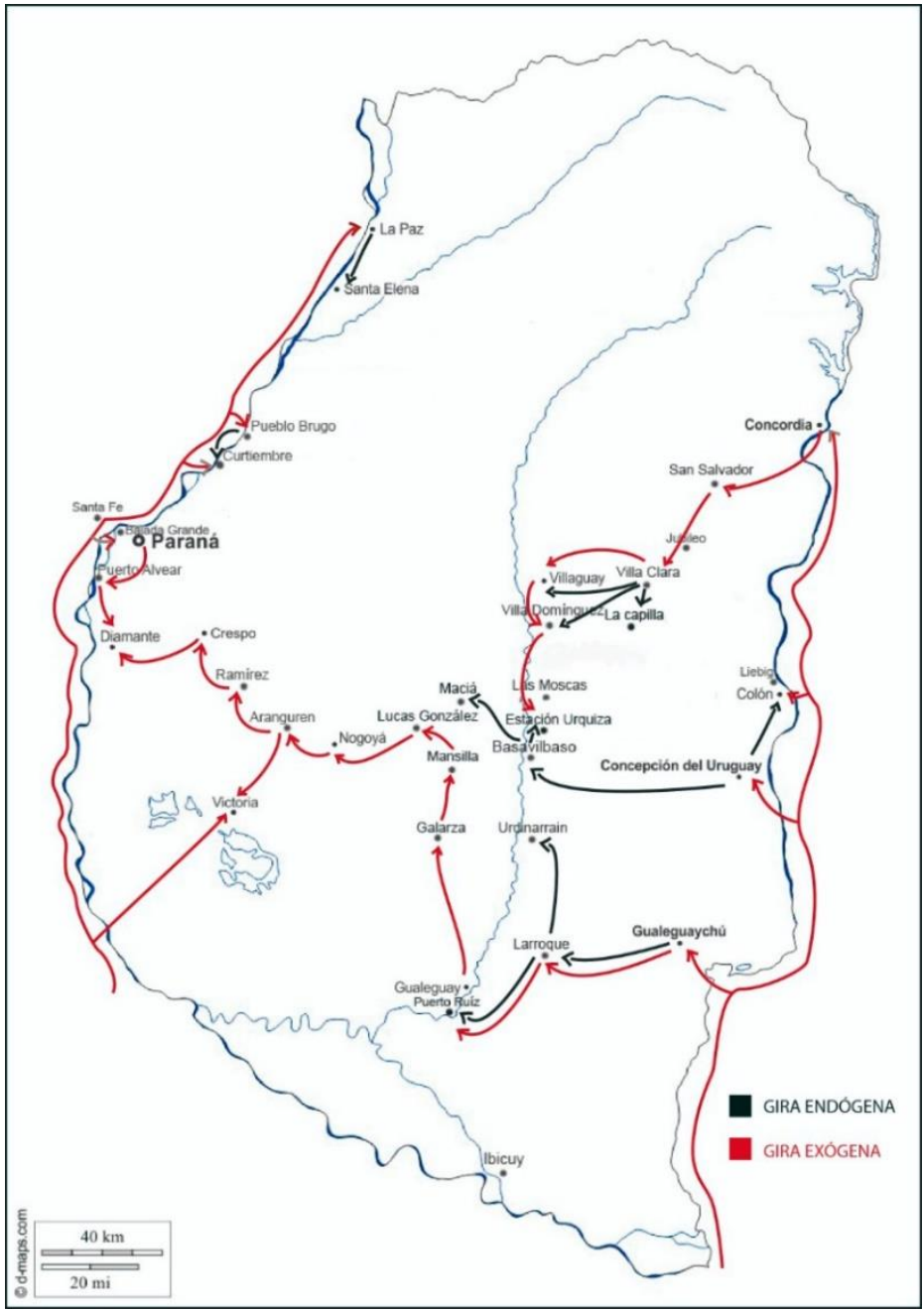

Fuentes: Elaboración propia sobre la base de los siguientes periódicos: $\mathrm{La}$ Vanguardia, Buenos Aires, órgano del Partido Socialista; La Organización Obrera, Buenos Aires, órgano de la Federación Obrera Regional Argentina, y La Protesta, Buenos Aires, periódico anarquista. 
El segundo ciclo de luchas y organización fue más extenso, fundamentalmente porque las organizaciones nacionales y locales eran más sólidas y hubo un cambio en el trato con el Estado.

La Figura 3 muestra el tímido inicio hacia 1927, coyuntura que se sostiene hasta que los efectos de la crisis económica y política de 1930 interrumpen el ascenso. Por ello, el año 1931 representa el punto más bajo. El año 1932 muestra el ascenso nuevamente, impulsado por la primera gira de la U.O.P.E.R., aunque la pérdida de la cosecha dificultó la ocupación de los obreros y la posibilidad de organizar nuevos sindicatos. La segunda y tercera gira fueron las que dieron los mayores resultados. En particular la gira de 1934-1935. Sin embargo, la crisis intestina de la U.O.P.E.R. que determinó la expulsión de los militantes de Diamante, detuvo la organización y empeorado por el fracaso de los conflictos de 1937. Recién en los años 1938-1939 se reinician las tareas de organización para levantar los sindicatos caídos en las últimas luchas.

Figura 3: Organización de sindicatos obreros en la provincia de Entre Ríos, 1927-1939

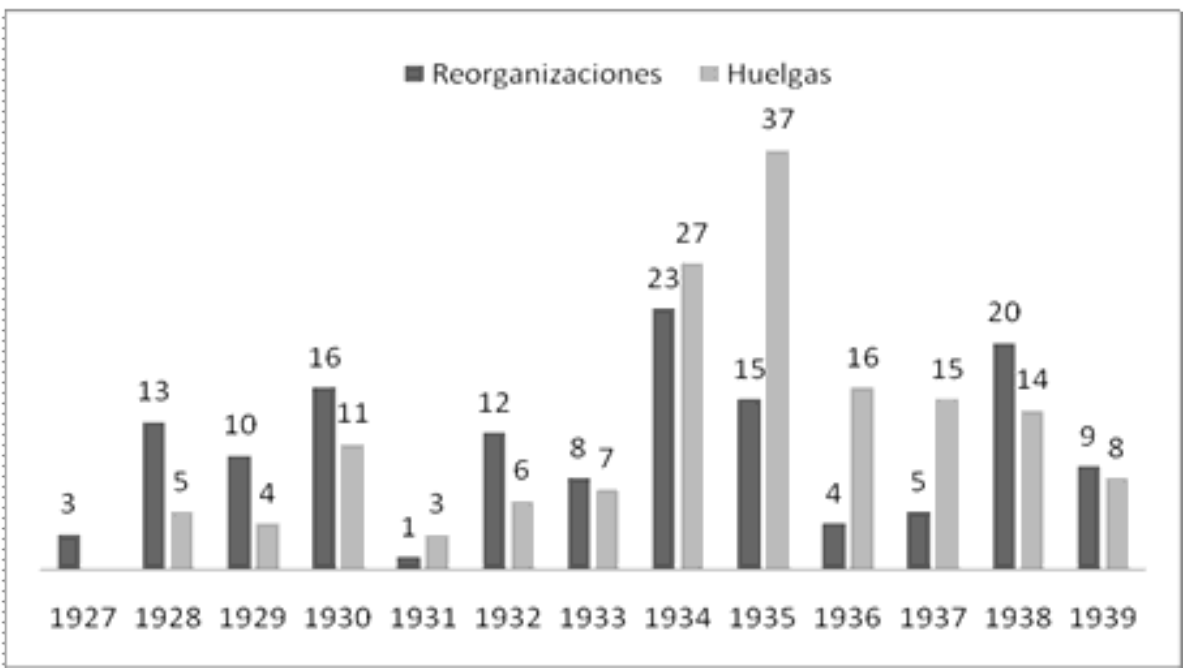

Fuentes: Elaboración propia sobre la base de los siguientes periódicos: Acción Libertaria, Buenos Aires, órgano de la Federación Anarco Comunista Argentina; Avance, Diamante, órgano de la Federación Obrera Comarcal Entrerriana; Bandera 
Proletaria, Buenos Aires, órgano de la Unión Sindical Argentina; Bandera Roja, Buenos Aires, periódico comunista; Boletín de la CGT, CGT (Catamarca), CGT, Buenos Aires, órganos de la Confederación General del Trabajo; El Argentino, Gualeguaychú; Crónica, Diamante; Debate, Gualeguay; Diario Del Pueblo, Colón; El Censor, Gualeguaychú; El Despertar, Concepción del Uruguay, órgano de la Unión Obrera de la Provincia de Entre Ríos; El Diario, Paraná; El Entre Ríos, Colón; El Litoral, Concordia; El Pueblo, Villaguay; La Acción, Paraná; La Juventud, Concepción del Uruguay; La Lucha, Paraná, órgano de la Federación Socialista de Entre Ríos; Los principios, Concepción del Uruguay; U.S.A. y Unión Sindical, Buenos Aires, órganos de la Unión Sindical Argentina, (2da época).

Al cuantificar los sindicatos creados por la obra de los delegados, sus resultados son elocuentes. De los ciento treinta y ocho sindicatos creados en cuarenta y cinco ciudades y pueblos ${ }^{46}$, solo ocho fueron fundados con militantes externos a la provincia. Los cuales intervinieron en los primeros tres años del ciclo estudiado y hacia el final, cuando los militantes de la U.S.A., en lucha contra el Partido Socialista, intentaron levantar un sindicato ferroviario paralelo ${ }^{47}$. Concluimos que el rol organizativo de los polos sindicales de la provincia reemplazó la función de los delegados exteriores a esta.

Con respecto al mapa (figura 4), reconocemos que la extensión territorial fue mayor que en el periodo anterior, y si bien la organización obrera mayoritaria se concentraba en la costa del río Uruguay, la apertura de nuevos ramales ferroviarios en el interior de la provincia facilitó llegar al noroeste provincial por las vías del Ferrocarril del Estado, en el eje transversal que tuvo a Diamante, en la costa del río Paraná, como el puerto de destino de la producción de Villa Federal al norte. En la representación cartográfica mostramos que predominó la iniciativa local frente a los impulsos externos.

\footnotetext{
${ }^{46}$ Arangueren, Arroyo Barú, Basavilbaso, Campichuelo, Cerrito, Cimarrón, Clé, Colón, Concepción del Uruguay, Concordia, Crespo, Diamante, Villa Domínguez, Echagüe, Estación Camps, Estación Durazno, Estación Raíces, Estación Tabossi, Estación Urquiza, Galarza, General Campos, Gualeguay, Gualeguaychú, Paraná, Puerto Brugo, Puerto Ruíz, Ramírez, Rosario del Tala, San Antonio, San Salvador, Seguí, Strobel, Tabossi, Ubajay, Urdinarrain, Viale, Victoria, Villa Clara, Villa Domínguez, Villa Federal, Villa Mantero, Villa San José, Villaguay e Ibicuy.

${ }^{47}$ El Despertar, Octubre de 1938, p.4.
} 
Figura 4: Recorrido de obreros en gira según su origen local o extra-provincial. Entre Ríos, 1927-1939

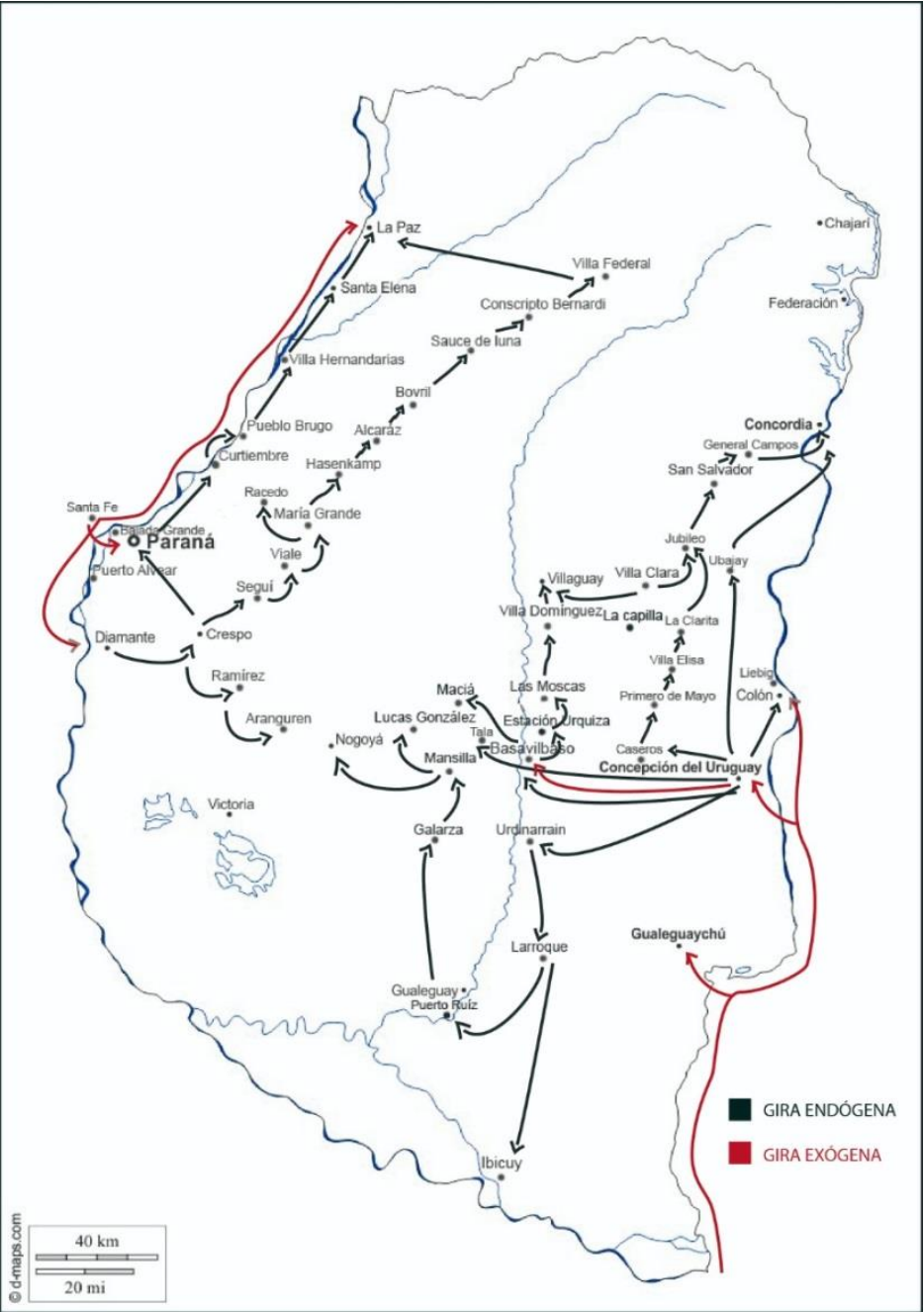

Fuentes: Elaboración propia sobre la base de los siguientes periódicos: Acción Libertaria, Buenos Aires, órgano de la Federación Anarco Comunista Argentina; Avance, Diamante, órgano de la Federación Obrera Comarcal Entrerriana; Bandera Proletaria, Buenos Aires, órgano de la Unión Sindical Argentina; Boletín de la CGT, CGT (Catamarca), CGT, Buenos Aires, órganos de la Confederación General del 
Trabajo; El Despertar, Concepción del Uruguay, órgano de la Unión Obrera de la Provincia de Entre Ríos; U.S.A. y Unión Sindical, Buenos Aires, órganos de la Unión Sindical Argentina, (2da época).

Antes de finalizar debemos considerar las fracciones obreras organizadas. Como la provincia de Entre Ríos es indudablemente una provincia agraria, las fracciones obreras serán las que corresponden a aquellas actividades, con la particularidad señalada de la temporalidad del trabajo. Esta condición agraria del proletariado entrerriano se presenta como una continuidad durante los dos ciclos de organización, y aunque concluimos que la organización obrera continuó asentada en el proletariado rural, durante el periodo de estudio 1917-1939, no podemos ignorar la importancia de la organización de algunas fracciones urbanas como fueron los obreros panaderos, gráficos, herreros, existentes en todos los pueblos y ciudades.

\section{Conclusión}

Las giras de organización fueron la respuesta a tres problemas que presentaba el territorio entrerriano: la dispersión demográfica originada por la condición agraria de la provincia, la debilidad de los organismos obreros por las condiciones de estacionalidad y, finalmente, la falta de militantes estables. Gracias a las giras de organización, las centrales sindicales, en este caso las de extracción sindicalista, lograban un vínculo orgánico entre los militantes de los grandes centros de agitación con los poblados más alejados. Así fue como, durante el periodo 1917-1922, la F.O.R.A. IXํㅗ se dio a la tarea de organizar al proletariado de todo el país, siendo Entre Ríos una de las provincias con mayor cantidad de visitas. Los resultados de aquellas giras, más de ochenta sindicatos creados en solo cinco años, demostraron que la estrategia como tal era eficaz al medio que se buscó organizar. Sin embargo, la ofensiva patronal y estatal desatada desde fines de 1920 demostró que la organización sindical entrerriana era débil y dependiente de las fuerzas exógenas de la provincia. Hecho que era reconocido por los militantes de la época. Hacia 1922 intentaron, vanamente, levantar los sindicatos caídos.

Hubo que esperar hasta 1927 para que las giras volvieran. Durante los primeros años de este ciclo ascendente, los militantes de fuera de la provincia funcionaron como verdaderos catalizadores que unificaron a viejos militantes locales. Rápidamente se organizaron dos polos sindicales, Diamante en la costa del Paraná y Concepción del Uruguay en la costa del 
río Uruguay. La crisis de 1930 detuvo el crecimiento, pero hacia 1932, la unificación de estos dos polos sindicales trajo a la vida a la U.O.P.E.R. Desde la central obrera de la provincia se realizaron tres grandes giras que constituyeron sindicatos en el interior provincial. Las rutas trazadas eran principalmente por las vías del ferrocarril que recorrían la provincia.

El resultado final, en una mirada histórica comparada entre los dos ciclos, reconoce que la estrategia fue apropiada y fructífera. Cuando pasamos números de las intervenciones advertimos la preeminencia de militantes exógenos al ambiente provincial durante el primer periodo (1917-1922) y la convivencia de experiencias locales que se truncaron con la represión. Mientras que en el segundo momento organizativo (1927-1939) reparamos que, al poco tiempo de iniciadas las gestiones de reorganización, los militantes locales obraron con autonomía y llevaron adelante la tarea. También es claro que, durante el segundo periodo, los cuadros vernáculos entendieron que se debía ajustar el vínculo con los sindicatos alejados de los polos sindicales, por ello pidieron la cotización, afiliación a la central provincial y nacional y, finalmente y más importante, el control de los pliegos de condiciones. Con todo esto se aseguraban el control y la dirección de las organizaciones sindicales.

También demostramos la persistencia de la tendencia sindicalista durante todo el periodo de estudio. Esta continuidad es de resaltar ya que, mientras perdían lugar en otras regiones del país, en la provincia de Entre Ríos se consolidaba. Esta continuidad política-ideológica se debe a varios factores, muchos de ellos exceden nuestro análisis específico, sin embargo, podemos ofrecer una respuesta más general.

Los sindicalistas no fueron los únicos que hicieron giras de organización por la provincia, como ya indicamos al principio de este trabajo. Ahora bien, el "éxito" de los sindicalistas se debió a una estrategia basada en una multiplicidad de elementos; en primer lugar, una modalidad estrictamente economicista que era apropiada para los empobrecidos obreros entrerrianos; en segundo lugar, la construcción de una estructura para la lucha económica que no los ubicaba como un peligro para el estado y, por último, el creciente reformismo de la corriente sindicalista los hacía una contención apropiada al desarrollo de otras tendencias como los comunistas (Leyes, 2019). Por último, una alianza tácita con los radicales que gobernaron la provincia durante todo el periodo de estudio, les dio libertad de acción. La conjunción de estos factores prolongó existencia de la 
corriente sindical dentro del territorio provincial, en contraste a su retracción en el ámbito nacional.

Por último, demostramos que se puede estudiar la formación del movimiento obrero tanto desde la órbita nacional como de la local sin escindir ambas perspectivas. Ambos territorios componen el todo que fue la historia del proletariado organizado. Si lo vemos en perspectiva, nos permite tener una mirada compleja sobre el surgimiento del peronismo como fenómeno histórico y dejar atrás, de una buena vez, esa historia (e historiografía) que sobreestima a Buenos Aires en detrimento del interior, al extrapolar experiencias y homogenizar situaciones diferentes, relacionar los niveles nacional-local y delimitar la extensión del movimiento obrero.

\section{Bibliografía}

Ansaldi, W. y Sartelli, E. (1993). Una conflictividad débil: los conflictos obreros rurales entrerrianos, 1918-1921. En W. Ansaldi (Comp.). Conflictos obreros rurales pampeanos, 1900-1937. CEAL (pp. 229238).

Arnaiz, M. (1991). Aires libertarios: la Federación Obrera Comarcal Entrerriana. 1920-1940. Anuario IEHS, (6), 283-300.

Ascolani, A. (2009). El Sindicalismo rural en la Argentina. Universidad Nacional de Quilmes.

Belkin, A. (2018). Sindicalismo revolucionario y movimiento obrero en la Argentina: de la gestación en el Partido Socialista al a conquista de la FORA (1900-1915). Imago Mundi.

Climent, G. y Mendes Diz, A. (1993). La industria azucarera y los comienzos del movimiento obrero en Tucumán. En T. Di Tella (Comp.). Sindicatos como los de antes... (pp.37-48). Biblos.

Díaz, H. (2008). Ramón Suárez Picallo. Años de Formación Política. Selección de textos (1916-1931). Editorial Alborada.

Díaz, H. (2009). Ramón Suárez Picallo. A voz esquecida do galleguismo, Comisión Irmáns Suárez Picollo. 
Díaz, H. (2014). Las giras sindicales como instrumento de construcción del movimiento obrero. La F.O.R.A. en Entre Ríos (1918-1921). Historia Regional, (32),

89-107. http://historiaregional.org/ojs/index.php/historiaregional/article/view/6

Entre Ríos. Ministerio de Gobierno. Dirección General de Estadística (1932). Síntesis estadística. Imprenta Oficial.

Etchenique, J, y Scandizzo, H. (2001). Apuntes para una historia del movimiento anarquista en el Alto Valle del Río Negro (1920-1930). Actas del IV Congreso de Historia Social y Política de la Patagonia Argentino-chilena, Trevelin, 15-17 de noviembre de 2001.

Etchenique, J. (2011). Pampa libre, anarquistas en la pampa argentina. Editorial Voces.

Gilbert, J. y Balsechi, E. (2008). Voces del sindicalismo entrerriano: memorias de la Unión Obrera Departamental de Concepción del Uruguay, 1918-1943. Ediciones del zorrito.

Gramsci, A. (2003) [1949]. Notas sobre Maquiavelo, sobre la política y sobre el Estado moderno. Ed. Nueva Visión.

Guzmán, H. (2013). Historia del socialismo en Santiago del Estero 18981920. Ponencia presentada en las XIV Jornadas Interescuelas/Departamentos de Historia. Departamento de Historia de la Facultad de Filosofía y Letras. Mendoza, 2-5 de octubre de 2013. Recuperada de: https://cdsa.aacademica.org/000-010/663.pdf

Kabat M. y Leyes R. (2018). Ciclos de luchas sindicales en la provincia de Entre Ríos, Argentina, 1930-1943. Estudios del ISHiR, (22), 1-20. Recuperado de:

https://ojs.rosarioconicet.gov.ar/index.php/revistalSHIR/article/view/862

Kabat, M. (2009). La sobrepoblación relativa. El aspecto menos conocido de la concepción marxista de la clase obrera. Anuario CEICS, (3), 109128. https://razonyrevolucion.org/secciones/anuario/A09kabat.pdf

Leyes, R. (2009). La estrategia de sindicalización de la F.O.R.A. del IXํo en el oriente entrerriano (1917-1921). Conflicto Social, (2), 34-48. http://biblioteca.clacso.edu.ar/Argentina/iigguba/20120621042526/conflicto_social_02.pdf 
Leyes, R. (2016). Caravanas de hombres marchaban: el éxodo obrero en Entre Ríos. 1925-1945. Folia histórica del Nordeste, (27), 9-38. http://revistas.unne.edu.ar/index.php/fhn/article/view/1215/1000

Leyes, R. (2017). Represión a la izquierda en la provincia argentina de Entre Ríos durante la Revolución de Junio, 1943-1945. Izquierdas, (32), 132-150.https://scielo.conicyt.cl/pdf/izquierdas/n32/0718-5049izquierdas-32-00132.pdf

Leyes, R. (2018). Detrás de la crisis: inversiones de capital, mecanización y desocupación en Entre Ríos, 1928-1946. Pampa, (17), 5579. https://doi.org/10.14409/pampa.v0i17.7701

Leyes, R. (2019). Un espectro se cierne sobre Entre Ríos: una aproximación a la acción de los comunistas en la provincia, 1931-1943. Estudios Sociales, (56), 61-84. https://doi.org/10.14409/es.v55i1.6700

Leyes, R. (2020) La experiencia anarquista de Diamante: Lucha de clases, represión y legislación obrera, 1929-1937. En A. Nieto y O. Videla (Comps.) El anarquismo después del anarquismo. Una historia espectral.

GESMAR. https://gesmar.estudiosmaritimossociales.org/editorial/coleccionanarquismos/el-anarquismo-despues-del-anarquismo/

Leyes, R. (2021). Cabezas de playa: los inicios del movimiento obrero en Entre Ríos, Argentina, 1893-1916. Mundos do Trabalho, (13), 1-24. https://periodicos.ufsc.br/index.php/mundosdotrabalho/article/view/76 $413 / 45452$

Marotta, S. (1961). El movimiento sindical argentino, su génesis y su desarrollo.Tomos II y III. Ed. Lacio.

Martínez Chas, M. (2009). Liderazgo Social y Militancia Comunista en la Provincia de Misiones: Una aproximación a la vida política e intelectual de Marcos Kanner. Centro de Estudios Avanzados (CEA)Universidad Nacional de Córdoba.

Marx, C. (2001) [1867]. El Capital. Fondo de Cultura Económica.

Mastrángelo, M. (2011). Rojos en la Córdoba obrera 1930-1943, Imago Mundi.

McGee Deutsch, S. (2003). Contrarrevolución en la Argentina. La Liga Patriótica Argentina, 1900-1932. Universidad Nacional de Quilmes. 
Oddone, J. (1975). Gremialismo proletario argentino. Libera.

Pianetto, O. (1983). Mercado de trabajo y acción sindical en la Argentina, 1890-1922. Desarrollo Económico, XXIV (94), 297-307.

República Argentina (1916). Tercer Censo Nacional, Tomo I, Antecedentes y comentarios, Buenos Aires, Talleres Gráficos L. J. Rosso y Cía.

República Argentina (1917). Tercer Censo Nacional, Tomo IV, Población, Buenos Aires, Talleres Gráficos L. J. Rosso y Cía.

República Argentina. Ministerio de Asuntos técnicos (1949). IV Censo General de la Nación. Censo Poblacional, Tomo I, Dirección del Servicio Estadístico, Buenos Aires.

Sartelli, E. (1993a). De estrella a estrella. De sol a sol. Huelgas de braceros en Buenos Aires, 1918-1922. En W. Ansaldi (Dir.) Conflictos obreros rurales pampeanos, 1900-1937, T. I. (pp. 64-128) CEAL.

Sartelli, E. (1993b). Rehacer todo lo destruido. Los conflictos obreros-rurales en la década 1927-1937. En W. Ansaldi (Dir.). Conflictos obreros rurales pampeanos, 1900-1937, T. III. (pp. 241-291). CEAL.

Sartelli, E. (2020). Confiar y esperar. El nacimiento de la burocracia sindical en la Argentina, 1917-1921. Ciclos, XXVII (54), 157-180. https://ojs.econ.uba.ar/index.php/revistaCICLOS/article/view/1749

Torre, J. C. (2011). La vieja guardia sindical y Perón. Ediciones RyR.

Unión Sindical Argentina (1924). Memoria y Balances del Comité Central presentados al $1^{\circ}$ Congreso Ordinario.

Unión Sindical Argentina (1926). Memoria y Balances del Comité Central presentados al $2^{\circ}$ Congreso Ordinario. 